\title{
La cadena perpetua en el ordenamiento jurídico italiano y argentino. Análisis y comparación
}

\section{POR MARIO CATERINI(*) Y MARIO EDUARDO MALDONADO SMITH(**)}

Sumario: I. La pena y su función.- II. La cadena perpetua bajo el perfil de los derechos humanos.- III. La cadena perpetua - ergastolo-en la legislación italiana.- IV. La jurisprudencia constitucional italiana.V. La cadena perpetua en la jurisprudencia del Tribunal Europeo de Derechos Humanos.- VI. Reflexiones sobre el ergastolo en la legislación italiana.- VII. La prisión perpetua en el ordenamiento jurídico argentino.- VIII. La jurisprudencia argentina frente a la prisión perpetua.- IX. Reflexiones sobre la cadena perpetua en el caso argentino.- X. Bibliografía.

Resumen: la cadena perpetua asume diversas modalidades, tanto en la legislación argentina como en la italiana. En estas modalidades se observan incompatibilidades con los derechos fundamentales y principios del derecho penal, tales como la razonabilidad, la proporción, la igualdad, la finalidad reeducativa de la pena y la culpabilidad. Asimismo, se analiza el instituto de la cadena perpetua como tal y se realizan diversas reflexiones en torno a su legitimidad en contextos de Estados libres y democráticos de derecho.

Palabras clave: cadena perpetua - ergastolo - reeducación - reinserción social - finalidad de la pena

(*) Prof. Titular de Derecho Penal, Universitá de la Calabria, Italia Dir. del Instituto de Estudios Penales "Alimena", Centro de Investigación Interdepartamental: www.unical.it/dices/ispa

(**) Prof. Derecho Penal Económico, Universidad Internacional de la Rioja. Asesor parlamentario en el Congreso de la Unión de México. 


\section{Life imprisonment in Italian and Argentinian law. A comparision}

Abstract: the life imprisonment assumes various modalities in Argentine and Italian legislation. In these modalities it's possible to find diverse incompatibilities with fundamental rights and principles of criminal law, such as reasonableness, proportionality, equality, the reeducational purpose of punishment and the culpability. Likewise, the institute of life imprisonment as such is analyzed and various reflections are made regarding its legitimacy in contexts of free and democratic states of law.

Keywords: life imprisonment - ergastolo - social reeducation - reintegration purpose of punishment

\section{La pena y su función}

Rudolf von Jhering señalaba que "la historia de la pena es una continua abolición" (1972, p. 269), en el sentido que progresivamente las sanciones han venido atenuándose, pasando de ideas retributivas, fundadas en el sufrimiento y la venganza, a otras que postulan la defensa de la dignidad de todo ser humano.

Tras la primera y la segunda guerra mundial, los derechos inherentes a la condición humana son retomados, reconociendo que existe un núcleo intangible que debe ser tutelado y que se encuentra más allá de toda consideración política, religiosa, mayoritaria o utilitarista (Maldonado Smith, 2015, p. 106 y ss.). La Constitución Italiana de 1948, en este contexto, reconoce y garantiza en su artículo 2 "los derechos inviolables del hombre".

Los derechos fundamentales suponen, como substrato esencial, la idea de dignidad humana (Höffe, 2001, p. 124). Es esta idea la que funda la necesidad de proteger una "esfera de lo indecidible" frente a cualquier poder que pueda amenazarla, sobre todo el del propio Estado (Garzón Valdés, 1993, p. 644; Ferrajoli, 2011, p. 775).

Además, la idea de dignidad se refiere no a un particular sujeto sino a cualquier ser humano, sin que para ello sea relevante alguna condición (Dworkin, 2007, p. 471; Nino, 1989, p. 43). Por ello, la dignidad debe ser respetada y garantizada, tanto al más ejemplar de los individuos como al más cruel y sanguinario de los delincuentes.

He aquí el punto de partida en la discusión del presente ensayo, la compaginación - no pocas veces difícil- entre el uso legítimo de la fuerza pública y el respeto a la dignidad del ser humano (Pulitanó, 2018, p. 1 y ss.). Más concretamente, la compatibilidad entre la ley penal y sus sanciones con el respeto a la condición humana, específicamente, tratándose de la cadena perpetua. 
La Carta de los derechos fundamentales de la Unión Europea prevé en su artículo 1 que la dignidad humana es inviolable y que debe ser respetada y tutelada. El artículo 2 del Tratado de la Unión Europea establece que esta se funda en los valores del respeto a la dignidad humana, la libertad, la democracia, la igualdad, el estado de derecho y el respeto de los derechos humanos. El artículo 10 del Pacto Internacional de Derechos Civiles y Políticos dispone que todo individuo privado de su libertad debe ser tratado con humanidad, en el respeto de la dignidad inherente a la naturaleza humana. La Constitución Italiana, en su artículo 3, párrafo 1, dispone que todos los ciudadanos tienen igual dignidad social y que son iguales frente a la ley.

De otra parte, al Estado corresponde garantizar la seguridad, el orden y la paz a los individuos, razón por la cual se justifica el uso del poder punitivo para reprimir las conductas que lesionan a la sociedad (Moccia, 1992, p. 109 y ss.; Mongillo, 2009, p. 175; Avitabile, 2014, p. 235 y ss.) y, al mismo tiempo, que la represión de las conductas delictivas sea realizada con respeto a la dignidad (Spangher, 2019, p. 1567; Ragimov, 2015, p. 103 y ss.).

Estas consideraciones valen, al menos, bajo la óptica de un sistema penal garantista que renuncia a una función meramente retributiva/aflictiva de la pena. Esta, como es sabido, no tiene una única función, si no, más bien, depende del sistema político y social en el cual se inscribe (Mongillo, 2009, p. 178; Naucke, 2002, p. 36; Nuvolone, 1982, p. 817; Marinucci, 1974, p. 50), de ahí que pueda ser utilizada como un instrumento de simple retribución, de intimidación general e individual o bien como un instrumento que permita la recuperación social de quien delinque y también de la sociedad (Moccia, 1992, p. 39 y ss.). Los Estados liberales y garantistas optan por dar prevalencia a estas últimas finalidades, reconociendo en la pena elementos dirigidos a la tutela del propio individuo y de la sociedad (Ragimov, 2016, p. 45; Mir Puig, 1999, p. 64; Lascano, 2005, p. 97).

El sistema italiano hace parte del modelo liberal garantista al reconocer en su Constitución (artículo 27, co. 3) que la pena - de entre las diversas funciones que puede tener (Zaffaroni, 2009, p. 20) — se dirige a la re-educación social del individuo, propósito central de las constituciones inspiradas en los principios del Estado social (Moccia, 1992, p. 83 y ss.; Mongillo, 2009, p. 174; Palombino, 2017, p. 2; Fiandaca, 1991, p. 342 y ss.).

La Corte Constitucional italiana, en su sentencia No 313 de 2 de julio de 1990, señalaba:

(...) la reintegración, la intimidación, la defensa social, son valores que tienen un fundamento constitucional pero que no es tal que permita autorizar la lesión de la finalidad reeducativa de la pena (...). Si la fina- 
lidad de la pena viniera orientada hacia aquellos otros diversos caracteres, antes que al principio de reeducación, se correría el peligro de instrumentalizar al individuo hacia fines generales de política criminal (prevención general) o de privilegiar la satisfacción de las necesidades colectivas de estabilidad y seguridad (defensa social), sacrificando al individuo a través de la ejemplaridad de la sanción.

La privación de la libertad de una persona como consecuencia de una pena no comporta una disminución en su condición humana (Zaffaroni, 2009, p. 44). Antes bien, es precisamente durante la privación de la libertad de una persona cuando frecuentemente la dignidad viene atropellada por las condiciones en las que el individuo se encuentra o por la misma condena que se le impone. Por ello, el Tribunal Europeo de Derechos Humanos (en adelante TEDU) en la sentencia Campbell e Fell vs. Reino Unido señaló que la tutela de los derechos fundamentales no puede "detenerse a las puertas de las prisiones".

En un contexto liberal y garante de la condición humana, algunas penas resultan, por decir lo menos, difíciles de justificar; la cadena perpetua es una de ellas.

\section{La cadena perpetua bajo el perfil de los derechos humanos}

Respecto de la cadena perpetua, Beccaria reconocía el gran carácter aflictivo que esta tenía sobre los individuos, reconociendo que la duración "a perpetuidad" de la sanción permite al individuo reflexionar sobre sus crímenes y provoca en él mucho mayor sufrimiento que la pena de muerte (Manacorda, 2015, p. 165 y ss.). En un parágrafo de Dei delitti e delle pena puede leerse: "si se me dijese que la esclavitud perpetua es tan dolorosa, y por tanto igualmente cruel que la muerte, responderé que sumando todos los movimientos infelices de la esclavitud lo será aún más; porque estos se reparten sobre toda la vida, y aquella ejercita toda su fuerza en un momento" (Beccaria, 2015, p. 59).

Como hemos indicado, en un contexto caracterizado por el reconocimiento de los derechos fundamentales, la dignidad se constituye como piedra angular bajo la que debe construirse el sistema penal. Todos los instrumentos internacionales que reconocen el monopolio legítimo de la fuerza estatal en el combate y la represión de los crímenes disponen que los mecanismos empleados por el Estado deben respetar esa dignidad, por lo que no son admisibles medidas contrarias al sentido de humanidad (la Constitución italiana lo reconoce literalmente en su artículo 27, párrafo tercero, y la argentina implícitamente en su artículo $18 \mathrm{y}$, explícitamente, mediante la correlación del artículo 75, inciso 22 de la Constitución Nacional (CN) y la Convención Americana sobre Derechos Humanos (en adelante CADH) en su artículo 11 (Petrino, 2013, pp. 203 y ss.). 
La persona privada de su libertad siempre es portadora de sus derechos inalienables. En consecuencia, la pena debe estar orientada a la garantía de esa dignidad (Fiorella, 2018, p. 110). En la mayor parte de los Estados constitucionales y democráticos de derecho, la pena se compatibiliza con la defensa de la dignidad mediante la idea de reinserción social (Scordamaglia, 2016, p. 110 y ss.; Mongillo, 2009, p. 179; Trapani, 2018, p. 1693 y ss.). La pena es vista como una herramienta dirigida a la recuperación y a lograr la reintegración del individuo en el tejido social; por tal razón, entre otras medidas, se reconoce - al menos en los Estados garantistas- la incompatibilidad de la pena de muerte, así como la implementación de medidas sancionatorias consistentes en tortura, tratos inhumanos, crueles o degradantes (Risicato, 2015, p. 1251; Pulitanò, 1981, pp. 155 y ss.). El principio de la reinserción social supone, como una lógica derivación, que un día el individuo podrá recuperar su libertad, siempre que, como resultado del tratamiento sancionatorio, demuestre una reorientación pro activa de respeto y convivencia social (Brucale, 2019, p. 1314).

La cadena perpetua, como originalmente fue concebida, se contrapone completamente a esta perspectiva de liberación. La perpetuidad es el reconocimiento de la incapacidad del Estado para lograr la reintegración social del individuo y deja a la pena con un carácter meramente aflictivo. La ratio de la cadena perpetua se reduce así a ser mera venganza, tormento y sufrimiento. Se renuncia a la concepción de la persona como fin en sí mismo y se le instrumentaliza para otros fines político/sociales (Mongillo, 2009, p. 176; Risicato, 2015, p. 1248; Vianello e Padovan, 1999, p. 247). Al final, esta pena no es en esencia muy diversa de la de muerte (Ragimov, 2016, p. 138; Pulitanò, 1981, pp. 155 y ss.); es la reclusión del individuo de por vida, su idea de fondo es la completa eliminación de la persona del contexto social (Dolcini, 2018, p. 25).

En regímenes totalitarios, que instrumentalizan al individuo con fines políticos o sociales, puede justificarse como medida de neutralización del individuo (Zaffaroni, 2009, p. 19 y ss.), pero no así en un sistema que apuesta por los derechos humanos, porque la cadena perpetua es la renuncia al ideal de la reinserción social sobre el que se funda la pena (Mosconi, 2008, p. 29; Ferrajoli, 1989, p. 292; Catedráticos de Derecho Penal, p. 18). En Estados liberales y garantistas, la pena privativa de la libertad es ya el corolario de la extrema ratio de la norma penal (Caterini, 2017, p. 102; Muñoz y García, 2002, p. 59), que viene a aplicarse no como una mera sanción retributiva sino como un instrumento dirigido tanto a la prevención de posteriores crímenes - prevención general positiva-, como a la reinserción social de quien delinque - prevención especial positiva - (Ferrajoli, 1985, p. 456 y ss.; Sgubbi, 1998, p. 36; Di Nuovo, 2012, p. 299).

La pena, como bien sabemos, puede tener un solo objetivo (la retribución) o tantos otros como se quiera, pero, en un sistema fundado en el respeto a los 
derechos inherentes a la persona, solo puede justificarse una pena dirigida a la protección de la persona, aún de aquella que ha cometido el más terrible de los delitos, pues ello no determina su estatus de persona ni menoscaba su dignidad (Franco Serrano, 2019, p. 408 y ss.).

\section{La cadena perpetua - ergastolo - en la legislación italiana}

En Italia, la cadena perpetua se denomina "ergastolo" y se encentra prevista como la máxima pena en el Código Penal (CP) - artículo 22- (Mosconi, 2008, p. 17; Pulitanò, 1981, pp. 158; Padovani, 2018, p. 27 ss.). Su aplicación se reserva a algunos delitos contra la personalidad del Estado (por ejemplo, el artículo $242 \mathrm{CP}$ ), contra la incolumidad pública, contra la vida (homicidio agravado, artículos 576 y $577 \mathrm{CP}$ ), el homicidio derivado de actos de tortura (artículo 613 bis) o derivado de secuestro con objeto de terrorismo, subversión o extorsión (artículo 289 bis, co. 3 y artículo 630 co. 3$)$.

A través de diversas reformas legislativas, el tratamiento de la persona condenada al ergastolo y la característica de la perpetuidad ha sido erosionado a tal grado que, hoy día, la persona condenada a dicha pena goza, en principio, de la posibilidad de acceder a diversos beneficios penitenciarios - como cualquier otra persona condenada-, por ejemplo, el trabajo en espacios abiertos, actividades recreativas y deportivas, el acceso a permisos premio, la semilibertad o la libertad condicional (Risicato, 2015, p. 1246). Este perfil delinea una primera versión del ergastolo que, como veremos, resulta ser multifacético.

En el año de 1962, mediante la ley de 25 de noviembre de 1962, № 1634, se admitió la posibilidad de conceder la liberación condicional a las personas condenadas al ergastolo (artículo 176, co. 3, CP), a condición de que se hubieren cumplido al menos 28 años de condena efectiva y siempre que durante tal periodo se hubiera demostrado una buena conducta (Brucale, 2019, p. 1308). Más tarde, en 1986, mediante la llamada "Reforma Gozzini" (ley 10 de octubre de 1986, № 663), el tiempo para solicitar la libertad condicional se redujo a 26 años y, adicionalmente, a los ergastolanos fueron concedidos otros beneficios (Dolcini, 2018, pp. 7-8).

En los años 90, Italia atravesó por un momento de gran violencia derivado fundamentalmente del combate a las organizaciones mafiosas y al terrorismo. Bajo este contexto fue aplicada la llamada "legislación de la emergencia" (Moccia, 1997 y 2009; Mongillo, 2009). En 1991, la ley de 12 de julio de 1991, № 203, creó el artículo 4 bis del Ordenamiento Penitenciario (en adelante OP). En este artículo se dispusieron las condiciones bajo las cuales los condenados que hubiesen cometido delitos particularmente graves (vinculados al terrorismo y a la asociación mafiosa) podrían acceder a medidas alternativas a la detención, así como otros 
beneficios. Los delitos enunciados en este artículo originalmente eran pocos y específicos; la colaboración con la justicia se disponía como un estímulo para acceder a medidas alternativas a la detención, disminuyendo los tiempos ordinarios que se requerirían para acceder a los mismos.

Más tarde, ante sucesos como el asesinato de los magistrados Giovanni Falcone y Paolo Borsellino, se reforzó la legislación de la emergencia, modificando el artículo 4 bis OP (Galliani y Pugiotto, 2017, p. 46; Travaglia Cicirello, 2019, p. 366) e incluyéndose en él una amplia categoría de delitos: mafia y terrorismo (incluido el internacional), subversión del orden democrático, tráfico de personas, explotación de la prostitución de menores y explotación de menores en la producción de material pornográfico, violencia sexual de grupo, secuestro de personas con objeto de extorsión, delitos en materia de droga y tráfico de migrantes. Sin embargo, la intervención más incisiva transformó completamente la ratio del artículo, pasando de un estímulo a una condición necesaria a fin de poder acceder a los beneficios penitenciarios. Se dispuso que los condenados a tales delitos no podrían ser admitidos a los beneficios penitenciarios ni a las medidas alternativas a la detención (con excepción de la liberación anticipada) si no colaboran útilmente con la justicia (excepto cuando la colaboración fuere imposible o irrelevante); he aquí el nacimiento del conocido "ergastolo ostativo" (Dolcini, 2018, p. 8; Pugliotto, 2017, p. 1518 y ss.).

Finalmente, el régimen de la excepcionalidad del ergastolo ostativo (artículo 4 bis $\mathrm{OP}$ ) venía a ser aún más excepcional mediante otra nueva forma de cadena perpetua (un ergastolo de tercer tipo), producto de la vinculación del artículo 4 bis y el 58 quater, co. 4, OP.

Este ergastolo, nacido con el propósito de hacer frente a una situación mediática, de alarma y peligro - siempre en el contexto de la permanente legislación de la emergencia- (Flick, 2009, p. 65), resultaba aplicable al delito de secuestro de personas con objeto de terrorismo, subversión o extorsión, seguido de la muerte de la víctima (artículo 289 bis co. 3 CP y artículo 630 co. 3 CP). El ceño distintivo de esta modalidad radicaba en que, además de la colaboración con la justicia, era necesario superar la barrera temporal dispuesta por el legislador consistente en la efectiva expiación de, al menos, 26 años de prisión para poder acceder a alguno de los beneficios penitenciarios del artículo 4 bis OP — queda fuera la libertad anticipada, ex artículo 54 OP- (Dolcini, 2018, p. 10; Galliani, 2018, p. 911),

Frente a los diversos tipos de ergastolo existentes en la legislación italiana, la jurisprudencia nacional e internacional ha tenido, en tiempos recientes, múltiples intervenciones que han llevado a declarar lo que ya desde hace mucho tiempo se evidenciaba, y es la oposición de estas figuras con principios centrales del ordenamiento italiano como la función reeducativa de la pena, el principio de 
racionalidad y de igualdad, así como la prohibición de penas contrarias al sentido de humanidad.

\section{La jurisprudencia constitucional italiana}

La Corte Constitucional italiana ha tenido oportunidad de pronunciarse en diversas ocasiones sobre el ergastolo, defendiendo, en principio, su compatibilidad con los principios constitucionales bajo diversas consideraciones. En el año de 1974, mediante la sentencia 21 de noviembre de 1974, № 264, la Corte Constitucional analizó la legitimidad del ergastolo en términos del artículo 27, co. 3 de la Constitución, concluyendo su compatibilidad bajo el argumento del carácter polifuncional de la pena y la eventual posibilidad de acceso a la liberación condicional (Mosconi, 2008, p. 25).

En el año 1994, mediante la sentencia de 28 abril, № 168, el ergastolo nuevamente viene atemperado, en esta ocasión respecto de su aplicabilidad a los menores de edad en términos del artículo 27, co. 2 y 31, co. 2 de la Constitución (protección de la infancia y la juventud). La Corte, en esta sentencia, nuevamente defiende en términos generales el instituto del ergastolo, considerando que no es más aquella figura prevista originalmente en el Código Penal de 1930 en tanto puede ser reducible y el condenado acceder a diversos beneficios que le permitan un día recuperar su libertad.

En el año 2003, mediante la sentencia de 9 de abril, No 135, la Corte analizó la figura del ergastolo ostativo, justificando su compatibilidad constitucional en tanto el carácter de perpetuidad puede ser reducido en aquellos casos en los que el condenado decide colaborar con la justicia. Además, argumentó que la elección de colaborar - o no- es una expresión de la libertad de la persona, de tal manera que no existe coacción, no se "constriñe" al individuo a declarar, es la libre elección la que determina el acceso a los beneficios y no una suerte de "automatismo legal"; por ello, no es un tratamiento deshumano, ni se opone al principio reeducativo del artículo 27, co. 3 de la Constitución (Dolcini, 2018, pp. 15-16).

A la par, en esa misma sentencia, la Corte respaldó lo que vendría a ser una presunción absoluta de peligrosidad para quienes no colaboran con la justicia (más allá de aquellos casos de colaboración imposible o irrelevante). En efecto, la disposición normativa permite considerar que la no colaboración evidencia un mantenimiento de los vínculos con la delincuencia, por lo que este mantiene el carácter de peligroso. De este modo, y reafirmando un parecer suyo desarrollado en la sentencia No 273 de 20 de julio de 2001, la Corte determinó que la voluntad de colaborar con la justicia es un mecanismo congruo que permite verificar la disolución del lazo que une a la persona con la asociación criminal “(...) solamente 
la elección de colaborar expresa con certeza la voluntad de enmienda que el ordenamiento penal debe tender a realizar".

En la sentencia No 149, de 11 de julio de 2018, la Corte Constitucional determinó la incompatibilidad de una de las formas de ergastolo (el régimen dispuesto por el artículo 58 quater, co. 4, OP en vinculación con el 4 bis, co. 1, OP), por contrastar con los principios de racionalidad e igualdad en el tratamiento penitenciario (artículo 3, Constitución Italiana) y por ser incompatible con la finalidad reeducativa de la pena (artículo 27, co. 3, Constitución Italiana). En esta forma de ergastolo, aun colaborando con la justicia, el condenado no podía tener acceso a los beneficios penitenciarios sino hasta pasados 26 años de condena efectiva y ello, de acuerdo con la Corte, resultaba contrario a la progresividad del tratamiento penitenciario dispuesto por la propia ley (artículos 21, 50, co. 4, 58, co. 4, OP y 176 Cód. Penal), blocándolo por ese lapso de tiempo. Además, la Corte consideró que se contradecía el principio de igualdad (artículo 3, Constitución italiana) porque creaba un régimen diverso que negaba a los ergastolanos los beneficios a los que sí pueden acceder otras personas condenadas al ergastolo. Finamente, en cuanto a la finalidad reeducativa de la pena (artículo 27, co. 3, Constitución Italiana), la Corte consideró que venía vulnerado porque el régimen aplicado hacía nugatorio el comportamiento realizado por el individuo en prisión. Solo la categoría objetiva del delito automatizaba la negación de beneficios penitenciarios y, sin duda, ello generaba también una apatía en el individuo por participar en su reinserción social, viniendo a menos la función de reeducación constitucionalmente prevista (Travaglia Cicirello, 2019, p. 365; Urbinati, 2018, p. 1100).

Más recientemente, en la sentencia № 253 del 23 de octubre de 2019, la Corte Constitucional se pronunció respecto de la ilegitimidad del artículo 4 bis, co. 1 , OP, en el caso de la exclusión de los "permisos-premio" a quien no colabora con la justicia. La Corte señaló que es correcto valorar positivamente a quien después de condenado presta una colaboración útil y eficaz, pero otra cosa, completamente desproporcionada e irracional, es la aplicación de un tratamiento penitenciario peor y que nada tiene que ver con el delito cometido, solo por el hecho de no colaborar: "Una cosa es la atribución de valor positivo al comportamiento de quien, incluso después de la condena, presta una colaboración útil y efectiva, otra cosa es la imposición de un tratamiento peor al detenido que no colabora, supuesto iuris et de iure como persona implicada en el crimen organizado y, por tanto, socialmente peligrosa" (considerato in dirito, 8.1).

La Corte reconoció, además, que la automática negación del acceso a los "permisos-premio" por la decisión de no colaborar violentaba el principio reeducativo de la pena porque impedía valorar de modo individualizado los progresos del condenado, negándole automáticamente el acceso a esos beneficios que han 
sido pensados precisamente como un instrumento para la reinserción social. Finalmente, la Corte indicó que la presunción de peligrosidad — derivada de la no colaboración- no puede ser absoluta, sino relativa y valorada, además, conforme a los progresos del individuo en su proceso de resocialización, así como en otros elementos que permitan dar certeza de que el individuo ha excluido su relación con la criminalidad.

La sentencia de la Corte Constitucional en relación a los permisos-premio es, sin lugar a dudas, de enorme trascendencia, pero no afronta aún el problema de fondo: la ostatividad (que permanece para los restantes beneficios penitenciarios previstos en el artículo 4 bis, co. 1 OP). La Corte, naturalmente, se pronunció únicamente respecto de los permisos porque fue esta la cuestión sometida a examen en la sentencia. Sin embargo, los razonamientos empleados por la Corte Constitucional resultan plenamente aplicables a los restantes beneficios penitenciarios.

\section{La cadena perpetua en la jurisprudencia del Tribunal Europeo de Derechos Humanos}

La Corte de Estrasburgo ha tenido también ocasión de pronunciarse sobre la cadena perpetua. Su jurisprudencia se ha enriquecido con el pasar de los años, reconociendo bajo determinadas características su compatibilidad con la Convención Europea de Derechos Humanos (CEDH o, en italiano, CEDU), en particular, con su artículo 3, que determina la prohibición de la tortura y las penas o tratamientos inhumanos o degradantes.

En la sentencia Kafkaris vs. Cipre, 12 febrero de 2008, el Tribunal Europeo de Derechos Humanos (TEDU) consideró que los Estados tienen la obligación, de acuerdo con los parámetros de la CEDU, de disponer la existencia de mecanismos de revisión - aunque no sean jurisdiccionales- y que permitan de iure y de facto la posibilidad de que el condenado pueda recuperar su libertad (Brucale, 2019, p. 1304).

En el año 2013, en la sentencia Vinter $v$ s. Reino Unido (sentencia de 9 de julio de 2013), el tribunal de Estrasburgo señaló que el condenado debe saber, desde el momento en que se le condena, aquello que debe de hacer a fin de alcanzar la posibilidad de una revisión de su condena. Se trata, en palabras del tribunal, de un derecho esencial a la "esperanza". Además, determinó que la decisión de la autoridad de poder reexaminar la situación del condenado debe estar motivada y debe ser previsto un recurso jurisdiccional en caso de negativa (Landa Gorostiza, 2017, p. 114 y ss.).

En 2017, derivado del caso Matiosaitis vs. Lituania (sentencia del 7 de junio), el Tribunal reafirmó que no basta la existencia de cualquier recurso para que la 
cadena perpetua pueda ser combatible con la Convención, es necesario un mecanismo que sea previsible y sujeto a revisión, de tal forma que un instrumento como la "solicitud de perdón", conferida al Presidente de la República de Lituania, no basta para considerar que este mecanismo es compatible con la CEDU porque tal instrumento está revestido de una total e ilimitada discrecionalidad (Galliani y Pugiotto, 2017, p. 34).

Más recientemente, el TEDU se ha pronunciado precisamente sobre el ergastolo ostativo en Italia, mediante la sentencia Viola $v$ s. Italia, del 13 de junio de 2019. En este caso, el Tribunal determinó que el ergastolo ostativo era una pena que, de facto, no era reducible, ya que en la hipótesis de que el condenado no colaborase con la justicia, la pena no permitía ninguna posibilidad de modificación y, además, convertía en irrelevante la conducta que el individuo hubiese desempeñado durante el tiempo de reclusión, contrastando esta situación con la dignidad inherente al ser humano tutelada por el artículo 3 de la CEDU (Santini, 2019, p. 1 y ss.).

La Corte Europea, además, determinó que la decisión de colaborar o no con la justicia no podía ser - como argumentaba el Estado- el resultado de una decisión libre y voluntaria del condenado (ante por ejemplo el temor fundado a posteriores represalias), ni equiparada como una permanente prueba de vinculación del individuo con la criminalidad. De ahí que la ausencia de la colaboración no podía ser considerada como un vínculo al cual subordinar la concesión de beneficios durante la ejecución de la pena y mucho menos podía impedir en modo automático la valoración de una progresiva reinserción del detenido en la sociedad (Mori y Alberta, 2019, p. 1 y ss.)

Como podemos ver, para el Tribunal Europeo de Derechos Humanos, lo que determina la compatibilidad o no de la cadena perpetua con la CEDU es la posibilidad de que este sea reducible de jure o de facto con lo que, en última instancia, viene a justificarlo siempre que no responsa más al carácter de la perpetuidad (Franco Serrano, 2019, p. 399 y ss.; Serrano Pérez, 2018, p. 109). En el fondo, la jurisprudencia del TEDU lo que reconoce es la inherente dignidad de todo ser humano, aún de aquellas personas condenadas por los más terribles crímenes, en tanto aún estos individuos son personas y tienen el derecho a la esperanza por recobrar algún día su libertad.

\section{Reflexiones sobre el ergastolo en la legislación italiana}

Hemos visto que, la legislación italiana prevé tres formas de ergastolo: el común, el del régimen de ostatividad y el de ostatividad agravada mediante el necesario cumplimiento de 26 años de prisión. 
La Corte Constitucional ha declarado la ilegitimidad de la tercera forma de ergastolo y, recientemente, se ha pronunciado en cuanto a la ilegitimidad de la segunda forma en relación con los "permisos-premio". El ergastolo común se mantiene y seguramente su suerte será la de permanecer aún en el ordenamiento italiano una vez señalada la compatibilidad de esta figura con la finalidad reeducativa de la pena y la CEDU en razón de su "reducibilidad".

Respecto de la forma de ergastolo previsto en el artículo 58, 4 co, OP (el tercer tipo), se evidenciaba ya desde mucho tiempo su incompatibilidad con los principios constitucionales, particularmente con la función reeducativa de la pena (artículo 27, co. 3, Constitución italiana) y el principio de igualdad (artículo 3 Constitución italiana). Este generaba una suerte de automatismo contrario al carácter dinámico e individualizado de la pena. Es decir, la pena no venía concebida como un instrumento dinámico en el que, a partir de los progresos individuales del individuo en su reinserción social, podía valorarse su acceso a diversos beneficios penitenciarios que lo llevarán un día a recobrar su libertad. La previsión del artículo 58 contrastaba completamente con esta perspectiva pues automáticamente decidía la suerte del individuo por 26 años independientemente de su comportamiento desplegado.

Ilógicamente, esta forma de ergastolo permitía el acceso a la liberación anticipada, una situación que en la práctica resultaba imposible pues para ello el juez debía valorar su progreso en el tratamiento penitenciario que, como se ha visto, dispone de una lógica progresiva (trabajo externo, permisos-premio, semi libertad y libertad condicional) (Galliani y Pugiotto, 2017, p. 5).

Por otro lado, la igualdad también venía sacrificada porque no existía ningún fundamento racional que permitiera justificar la disparidad de tratamiento existente entre el régimen dispuesto por el artículo 58, co. 4 . y el 4 bis, co. 1, del OP, no se diga ya en el caso de los ergastolanos comunes, a quienes no resultaba aplicable ninguno de los dos regímenes anteriores (Galliani, 2018, p. 911).

El ergastolo también vulneraba flagrantemente el principio constitucional contenido en el artículo 13, co. 4, de la Constitución, donde se prevé la prohibición de toda violencia física y moral sobre las personas sometidas a restricción de libertad. En efecto, la obligatoria expiación de 26 años de pena sin importar en absoluto la conducta desplegada por la persona en prisión, venía a ser mera aflicción, arbitrio y sufrimiento. En este panorama, la pena dejaba de ser legítima para constituirse en una violencia irracional del Estado, que bien podía calificarse de tortura (Chinnici, p. 10). El individuo, hiciera lo que hiciera, aún incluso colaborar con la justicia, era considerado en abstracto peligroso, solamente en razón del tipo de delito cometido. La finalidad de la pena era, por un lado, la de intimidación social a quien cometiera ese tipo de delitos (prevención general negativa) y, por el 
otro, de carácter retributivo en tanto que por el delito cometido debían cumplirse inexorablemente al menos 26 años de cárcel. El Estado, mediante esta previsión normativa, expropiaba automáticamente lo que constituye aproximadamente un tercio de la vida media de una persona, con el único objetivo de castigarlo (Galliani y Pugiotto, 2017, p. 21).

En cuanto a la segunda forma de ergastolo, el ostativo (artículo 4 bis OP), supone no ya un elemento temporal sino un parámetro eminentemente subjetivo, que es la colaboración con la justicia, y que se constituye como una condición necesaria para el acceso a los beneficios penitenciarios, más allá de la colaboración imposible o irrelevante.

En pasado, la Corte Constitucional defendía su legitimidad constitucional en virtud del carácter reducible de la perpetuidad, en tanto esta podía venir a menos si se decidía colaborar con la justicia. Bajo una idílica manifestación de la "libre elección" de la persona, se justificaba que colaborar era un símbolo de la voluntad de cambio del sujeto (Bontempelli, 2017, p. 1527 y ss.).

Sin embargo, la colaboración - o no- con la justicia es un proceder que no per se puede ser calificado como una condición absoluta para determinar la peligrosidad del individuo (Dolcini, 2017, p. 1500). Más aún, poco tiene que ver con una lógica de reeducación del sujeto, pues resulta evidente la posibilidad de colaborar por motivos meramente instrumentales que permitan acceder a una eventual liberación. La colaboración, antes bien, carece de toda lógica en un sistema teleológico orientado a la reeducación del delincuente, pues, en caso de no colaborar, se niega toda esperanza a la recuperación social (Pugliotto y Musumeci, 2015, p. 82 y ss.).

La colaboración con la justicia fue pensada originalmente como un instrumento de incentivación que, de una parte, permitía reducir los tiempos normales para el acceso a ciertos beneficios penitenciarios: estos no venían negados en caso de no colaborar, simplemente seguían su temporalidad normal (Risicato, 2015, p. 1248). La incoherencia derivada de la modificación legislativa al artículo 4 bis OP, en 1992, fue que el "colaborar" pasó a ser la única posibilidad para acceder a una eventual liberación, sin tomar en consideración las múltiples razones por las que una persona puede decidir no colaborar: el temor fundado de una represalia en carne propia o dirigía a familiares o seres queridos; el deseo de no sacrificar a otra persona a cambio de sí mismo o, simplemente, la libertad moral de no acusar a nadie (Chinnici, 2015, p. 5).

El postulado idílico de la libertad del hombre para decidir colaborar o no, en el fondo, no era así (o al menos no en todos los casos), porque no puede ser libre quien teme que su colaboración provoque represalias a sí mismo o a las personas 
queridas, o bien, que procediendo en tal modo traiciona su conciencia y los valores en los que fundamenta su proceder.

La colaboración con la justicia no puede ser un criterio absoluto para determinar la voluntad de cambio de la persona condenada ni mucho menos dar lugar a un automatismo legislativo respecto de las consecuencias jurídicas relativas a la concesión, o no, de los beneficios penitenciarios (Palombino, 2017, p. 11). Como hemos señalado, una persona puede tener toda la voluntad de cambio para reintegrarse en la sociedad y, no obstante, decidir no colaborar con la justicia por alguna particular razón. A la inversa, uno puede colaborar, sin tener una real voluntad de cambio, sin haberse arrepentido jamás por el crimen realizado y utilizarla solo como una estrategia para la reducción de la condena, para salir de prisión y regresar a la vida criminal (Galliani y Pugiotto, 2017, p. 55).

La ostatividad fue un acto de rabia, impotencia y de venganza hacia la criminalidad (se piense en el asesinato de Giovanni Falcone o de Paolo Borsellino), su finalidad fue la de crear un "confesionario" para desmantelar las organizaciones criminales y mafiosas, golpeándolas desde su interior, permitiendo los beneficios penitenciarios solo a aquellos "arrepentidos" que confesaran. De ahí que también puede ser visto como una violación a la dignidad humana porque instrumentaliza a la persona (Dolcini, 2018, p. 16; Brucale, 2019, p. 1308).

El individuo debe ser sancionado únicamente por la conducta desplegada en pasado y que haya lesionado bienes jurídicos (Moccia, 1995, p. 343; Caterini, 2004, p. 331; Cavaliere, 1998, p. 85). Mediante el requisito de la cooperación con la justicia, lo que sucede es que el individuo viene ulteriormente sancionado, no ya por lo que ha hecho sino por ser un tipo particular de persona, es decir, aquella que no colabora con la justicia, que decide guardar silencio jejercitando un derecho fundamental! En suma, se trata de un tipo penal de autor (Caterini, 2016, p. 155; Zaffaroni, 2009, p. 37; Ragimov, 2015, p. 91 y ss.), en el que el castigo por no colaborar (la perpetuidad) resulta ser aún más grave que el delito cometido (Musumeci, 2012, p. 38).

Por si fuera poco, el ergastolo ostativo también presenta problemas en relación a los tipos penales a los que puede venir aplicado. El artículo 4 bis OP, otrora limitado a su aplicación en casos vinculados con la asociación mafiosa y el terrorismo, hoy día se caracteriza por la heterogeneidad de delitos a los que resulta aplicable y que poca relación uniforme guardan entre sí. La ausencia de uniformidad en estos tipos penales ya en sí plantea serias dudas en cuanto al cumplimiento de los principios de racionalidad, proporcionalidad e igualdad en la aplicación de la ley penal. El 4 bis es una vez más una clara muestra de la discrecionalidad del legislador en la construcción de reglas penales irracionales y, además, contrarias a la 
Constitución, pues manifiestamente sobrepasa el límite formal y material del que dispone en la elaboración de los tipos penales (Fiorentin, 2019, p. 1606).

La Corte Constitucional ha reconocido mediante la sentencia No 253 del 23 de octubre de 2019 las incompatibilidades del ergastolo ostativo con la Constitución, pero lo ha realizado únicamente respecto de la materia objeto de la consulta que se le ha presentado (los permisos-premio), manteniéndose aún la ostatividad respecto de los demás beneficios penitenciarios dispuestos por el artículo 4 bis OP. Las razones que han guiado a declarar la ilegitimidad constitucional objeto de la consulta, con toda lógica pueden ser extrapoladas al instituto del ergastolo ostati$v o$ en su generalidad.

\section{La prisión perpetua en el ordenamiento jurídico argentino}

La Constitución de la Nación (CN) establece en artículo 18 que "las cárceles de la Nación serán sanas y limpias, para seguridad y no para castigo de los reos detenidos en ellas, y toda otra medida que a pretexto de precaución conduzca a mortificarlos más allá de lo que aquella exija, hará responsable al juez que la autorice" (Quiroga Lavié, 2009, p. 440).

A la par, el artículo 75, inc. 22, recoge diversos tratados internacionales en materia de derechos humanos y dispone su jerarquía constitucional, entre estos: la Convención Americana sobre Derechos Humanos (en adelante, CADH), el Pacto Internacional de Derechos Civiles y Políticos y la Convención contra la tortura y otros tratos o penas crueles, inhumanos o degradantes.

La CADH prohíbe, en su artículo 5, inciso 2, la imposición de "penas crueles, inhumanas o degradantes", y el inciso 6 dispone que "las penas privativas de la libertad tendrán como finalidad esencial la reforma y readaptación social de los condenados". Similar previsión puede encontrase en el artículo 10.3 del Pacto Internacional de Derechos Civiles y Políticos.

La Ley de ejecución penal (ley 24.660), tras las reformas introducidas por la ley № 27.375 (B.O. 28/07/2017), dispone, en su artículo 1, que

La ejecución de la pena privativa de libertad, en todas sus modalidades, tiene por finalidad lograr que el condenado adquiera la capacidad de respetar y comprender la ley, así como también la gravedad de sus actos y de la sanción impuesta, procurando su adecuada reinserción social, promoviendo la comprensión y el apoyo de la sociedad, que será parte de la rehabilitación mediante el control directo e indirecto. 
Igualmente, el artículo 6 de dicha ley establece el "régimen de progresividad" y el artículo 12 lo desarrolla señalando cuatro periodos: la observación, el tratamiento, la prueba y la libertad condicional (Curotto, 2012, p. 9).

Los principios constitucionales, así como la normativa internacional a la cual se ha sujetado el Estado argentino, permiten concluir que el ordenamiento penal excluye completamente cualquier pena con el único fin de castigo (Zaffaroni, 1995, p. 115) y que, por tanto, la pena solo puede estar dirigida a la resocialización. La Corte Suprema de Justicia de la Nación (CSJN) ha expresado que, a la par de garantizar la seguridad, como un deber primario del Estado "importa también resguardar los derechos de los penados, cuya readaptación social se constituye en un objetivo superior del sistema y al que no sirven formas desviadas del control penitenciario" (caso Badín, sentencia de 19 de octubre de 1995, fallos 318: 2002).

En lo que hace a la prisión perpetua, se encuentra prevista dentro del Código Penal de la Nación (en adelante, CP) en sus artículos 6, 9 y 13. Los aspectos relativos a su implementación, por su parte, quedan regulados por la ya mencionada ley 24.660 (Quiroga Lavié, 2009, p. 441).

La pena perpetua se prevé para los delitos considerados de mayor reproche social (Argenti y Blanco, 2015, p. 242), entre estos: casos de homicidio agravado (artículo $80 \mathrm{CP}$ ), delitos contra la integridad sexual seguidos de la muerte de la víctima (artículo $124 \mathrm{CP}$ ), secuestro con posterior muerte dolosa de la víctima (artículos 142 bis y $170 \mathrm{CP}$ ), delitos contra la seguridad de la nación (artículos 215 y $227 \mathrm{CP}$ ); espionaje y sabotaje al servicio de una potencia extranjera (artículo 2 ley 13.985); extracción ilegal de órganos y tejidos humanos vivos (artículo 30 ley 24.193); desaparición forzada de personas, seguida de la muerte de la víctima, o si esta fuere una mujer embarazada, un menor de edad, persona con discapacidad, mayor de 70 años o, cuando la víctima sea una persona nacida durante la desaparición forzada de su madre (artículo 143 ter CP); genocidio, crímenes de lesa humanidad y crímenes de guerra (artículos 8, 9 y 10 ley 26.200).

Puede advertirse que las conductas típicas a las cuales se aplica la pena perpetua resultan ser sumamente heterogéneas, pero, adicionalmente, también resulta sumamente complejo el tratamiento penitenciario al que pueden, o no, acceder las personas condenadas en virtud del tipo penal en el que su conducta haya sido encuadrada. De este modo, en cuanto a la aplicación del tratamiento penitenciario, la pena perpetua puede catalogarse de la siguiente manera: 1) prisión perpetua con posibilidad de acceder a la libertad condicional (artículo 13 CP);2) prisión perpetua sin posibilidad de acceder a la libertad condicional pero con posibilidad de acceder a la libertad asistida (artículo 54 ley 24.660, siempre que no se trate de un delito dispuesto en el artículo 56 bis de la misma ley); 3) prisión perpetua sin posibilidad de libertad condicional, beneficios del periodo de prueba, prisión 
discontinua, ni libertad asistida, es decir, el régimen penitenciario más duro, exacerbado por la ley 27.375 y reservado para los delitos dispuestos en el artículo 56 bis de la ley 24.660; 4) penas temporales de prisión con límite máximo de 50 años, y 5) reclusión accesoria por tiempo indeterminado (Gobbi, 2014, p. 1 y ss.).

En principio, la pena perpetua es reducible de acuerdo con el artículo 13 del $\mathrm{CP}$, el cual dispone que, tras treinta y cinco años, podrá accederse a la libertad condicional siempre que se hubieren cumplido con regularidad los reglamentos carcelarios y que se pronostique en forma individualizada y favorable su reinserción social. En esta hipótesis y, de acuerdo con el artículo 16 CP, después del plazo de cinco años de la condicional, la pena quedará extinguida.

Además, la ley 24.660, no sin diversas contradicciones, dispone que, durante el cumplimiento de esos 35 años, el condenado podrá acceder a diversos beneficios penitenciarios, tales como salidas transitorias al exterior, cursar estudios o, participar en programas de prelibertad (una vez cumplidos 15 años de condena) para trabajar o acceder al régimen de libertad asistida (artículos 16, 17, 23, 30 y 54, ley 24660, siempre que no se trate de los delitos dispuestos por el artículo 56 bis).

La ley No 27.375 de reforma a la ley 24.660 , en efecto, vino a modificar, entre otros tantos, el artículo 17 antes señalado, modificando los anteriores plazos y requisitos para el acceso al régimen de semilibertad, en modo tal que la actual disposición tiene el efecto que para los delitos con penas superiores a los 5 años de reclusión la libertad condicional pueda darse incluso antes que las salidas transitorias, con el consiguiente efecto de que la "progresividad" del tratamiento sancionatorio deja de ser gradual (Figari y Herrera, 2017, p. 23).

Cabe señalar que el límite temporal de 35 años fue colocado en el año 2004, siempre en un contexto de permanente emergencia como resultado de la presión ejercida por la opinión pública tras un conocido caso (Axel Blumberg), y que motivó el aumento de la barrera temporal, originalmente fijada en 20 años, a 35 (Alagia, 2014, p. 103). La normativa emergencial más tarde recobro impulso mediante las reformas de amplio espectro punitivo introducidas con motivo de la ley 27.375 de reforma a la ley 24.660. En efecto, el principal promotor de la reforma - el diputado Alfonso Petri- señaló que esta se sustentaba

(...) porque hay un reclamo constante y reiterado de la ciudadanía en el sentido de cerrar la puerta giratoria [y porque] vemos que muchísimos delincuentes que cumplen sus condenas y a la mitad de ellas obtienen los beneficios de las salidas transitorias o de la utilización del régimen de semilibertad, terminan cometiendo delitos cuando deberían estar cumpliendo sus penas (Alderete, 2017, p. 3). 
Como hemos adelantado, la figura de pena perpetua en su modalidad básica viene a ser modelada por diversas disposiciones del código penal y de la ley 24.660, que impiden a diversas categorías de condenados el acceso a los beneficios penitenciarios antes señalados. Así, en primer lugar, el artículo 14 del CP dispone que la libertad condicional (regulada por el artículo 28 de la ley 24660) no se concederá a los reincidentes (artículo $50 \mathrm{CP}$ ), ni tampoco a quienes fueran condenados por diversos delitos señalados en ese mismo artículo, muchos de los cuales normalmente son penados con la cadena perpetua (Alagia, 2014, p. 102). A la par, para el acceso a la libertad condicional, el artículo 28 de la ley 24660 prevé, tras la reforma de 2017, diversos requisitos adicionales, así como un estudio detallado y meticuloso del pronóstico de reinserción social, el cual podrá ser favorable o desfavorable; sin embargo, se advierte un rigor que eventualmente podría dificultar el acceso a la libertad condicional (Figari y Herrera, 2017, p. 27).

El régimen de la libertad asistida (regulado por el artículo 54 de la ley 24.660), que permite el egreso anticipado y el reintegro al medio libre, también viene negado por el artículo 56 bis de la misma ley en el supuesto de diversos delitos que también pueden ser sancionados con cadena perpetua y exasperada con motivo de la Ley 27.375 (Gobbi, 2014, p. 1 y ss.); pero no solo se niega la libertad asistida, sino también el acceso a beneficios penitenciarios comprendidos en el periodo de prueba, la prisión discontinua o la semidetención (artículos 30 y 31, ley 24.660). Si a esta previsión se agrega el artículo 14 del CP, que niega la libertad condicional a los reincidentes y a muchos de los casos previstos en el artículo 56 bis, para el caso de un condenado al ergastolo, en la práctica se le niega toda posibilidad de recuperar un día su libertad, pues deberá cumplir la totalidad de la condena que, en este caso, es hasta la muerte.

También debe indicarse que, con motivo de la reforma a la ley 25.928, el artículo $55 \mathrm{CP}$ dispone que cuando concurrieren varios hechos independientes reprimidos con una misma especie de pena, la pena aplicable al reo tendrá, como mínimo, el mínimo mayor y, como máximo, la suma aritmética de las penas máximas correspondientes a los diversos hechos. Sin embargo, esta suma no podrá exceder de 50 años de reclusión o prisión. En esta hipótesis de concurso de delitos, el legislador ha fijado el límite máximo a la pena, que resulta ser de 50 años (Curotto, 2012, pp. 21-22).

Finalmente, el artículo 52 del Código Penal dispone la posibilidad de aplicar la reclusión por tiempo indeterminado, como sanción accesoria a la condena, en casos de reincidencia múltiple. Esta figura en el ordenamiento jurídico argentino es vista no cómo una pena sino como una medida de seguridad, fundada en la peligrosidad del individuo (Gobbi, 2014, p. 1 y ss.). 


\section{La jurisprudencia argentina frente a la prisión perpetua}

Los tribunales argentinos han abordado el tema de la prisión perpetua bajo diversas perspectivas, no existiendo actualmente un criterio uniforme respecto de su legitimidad o no, aunque en los últimos años se evidencia una cierta tendencia contraria a su implementación, particularmente en cuanto a la condición agravante resultante de la aplicación de los artículos 56 bis y 80 del CP.

A nivel de la Corte Suprema de Justicia de la Nación (CSJN), la cadena perpetua es, en términos generales, reconocida como compatible con la Constitución y la $\mathrm{CADH}$, en tanto se admite la eventual posibilidad de acceso a la libertad condicional y a otros beneficios penitenciarios. En el año 2005, la CSJN a través del caso "Maldonado, Daniel Enrique y otros/Robo agravado por el uso de amas en concurso real con homicidio calificado" (Fallo 328: 4343 del 7 de diciembre de 2015), determinó la inconstitucionalidad de la prisión perpetua aplicada a menores de edad, con fundamento en el principio de reinserción social de la pena y el interés superior del menor. No obstante, en el caso de los mayores de edad, la Corte justificó la legitimidad de la prisión perpetua, con base en el principio de estricta legalidad al que deben sujetarse los jueces, por lo que se debían respetar las consecuencias jurídicas previstas por el legislador (Bazán 2010, p. 359; Elhart, pp. 3-4; Lauría Masaro, 2015, p. 54).

En 2006, la CSJN, en la causa “Giménez Ibáñez, Antonio Fidel”, fallos 329: 2440, del 4 de julio de 2006, se pronunció respecto de la necesidad de fijar un límite temporal a la pena, argumentando que la pena privativa de libertad realmente perpetua lesionaba la intangibilidad de la persona humana en razón de que generaba graves trastornos de la personalidad, por lo que resultaba incompatible con la prohibición de toda especie de tormento consagrada en el artículo 18 de la Constitución (Quiñones Allende, 2013, p. 3; Racca, 2014, p. 15; Ejecución de penas, 2014, p. 22).

En el caso "Gramajo, Marcelo Eduardo s/robo en grado de tentativa" (fallos 324: 2153, del 5 de septiembre de 2006) la Corte Suprema declaró la inconstitucionalidad de la reclusión accesoria por tiempo indeterminado (artículo $52 \mathrm{CP}$ ), señalando que esta no era una medida de seguridad sino una pena y que no podía sustentarse bajo la peligrosidad de la persona. También sostuvo que vulneraba el principio de culpabilidad, de proporcionalidad de la pena, de reserva, de legalidad, el derecho penal del acto y la prohibición de imponer penas crueles, inhumanas y degradantes (Curotto, 2012, pp. 7 y ss.; Argenti y Blanco, 2015, p. 247; Bessone y Durán, 2014, pp. 3 y ss.).

En el caso "Estévez, Cristian Andrés o Cristian Daniel s/robo calificado por el uso de armas" (fallos 333: 866, sentencia del 8 de junio de 2010) la CSJN, representada 
por Zaffaroni en su voto en disidencia, cuestionó ampliamente la legitimidad de la pena perpetua. Indicó que en el ordenamiento argentino la pena de muerte está prohibida y no puede ser restaurada por vía de un equivalente. En su razonamiento, Zaffaroni también afirmó que en un sistema republicano la pena siempre debe tener un límite temporal, por lo que no es admisible una consecuencia jurídica que inhabilita durante toda su vida a una persona

(...) de aceptarse lo contrario, la ley estaría creando una capitis deminuitio o la muerte civil, con la consecuencia que de ello daría lugar a una categoría de ciudadanos degradados, marcados a perpetuidad, estigmatizados de por vida, para los cuales la posibilidad de rehabilitarse civilmente sería imposible (...) no es posible entender qué posibilidad de readaptación social puede tener una persona si en la mayoría de los casos al término de la pena ya no será persona por efecto de la muerte o, incluso en los excepcionales casos en que tal evento no se produzca, se reincorporará a la vida libre cuando haya superado la etapa laboral, además de cargar con la incapacidad del deterioro inocuizante de semejante institucionalización (Considerando 7 y 33 del voto particular de Zaffaroni) (se vea también Rodríguez Yagüe, 2016, p. 97).

En la misma sentencia, el Juez Mario Juliano reforzó las consideraciones de Zaffaroni indicando:

La imposición de una pena de prisión perpetua a los señores Etcheverry, Varela y Gonzáles importaría, lisa y llanamente, condenarlos a morir en prisión. Si es que alguno de ellos logra superar con vida el tiempo de encierro necesario para tener la posibilidad de solicitar su liberación condicional, por la edad que tendrán en ese momento (91, 75 y 71 años), el encierro les habrá consumido su capacidad productiva y la resocialización proclamada será una evidente quimera (Considerando 24 del voto particular del juez Juliano).

En 2007, la Cámara 11 Criminal de Córdoba, en el caso "Bachetti Sebastián Alejandro y otra p.ss.aa de Homicidio calificado por el vínculo" (sentencia del 2 de noviembre), reconoció la ilegitimidad del régimen previsto para la libertad condicional. La Cámara argumentó que era irrazonable y desproporcionado el tiempo de 35 años para poder acceder a la condicional, violentando el principio constitucional de proporcionalidad de la pena en relación a la culpabilidad del agente (González Stier, 2018, p. 3; Argenti y Blanco, 2015, p. 245).

En el año 2012, la Sala II de la Cámara Federal de Casación Penal, en el caso "Montiel, Alejandro Héctor" (sentencia del 26 de noviembre) rechazó la imposición de una pena sin un límite temporal y fijo al condenado una pena de 25 años por ser esta la máxima prevista para los casos de crímenes de lesa humanidad, 
crímenes de genocidio y crímenes de guerra previstos en la ley 26.200 (Argenti y Blanco, 2015, p. 248).

En el caso "Etcheverry, Daniel; González, C, y Varela, M. s/homicidio calificado por el concurso premeditado de dos o más personas; lesiones graves culposas y robo", el Tribunal Criminal No 1 de Necochea, mediante su sentencia de 13 de mayo de 2013, determinó la inconstitucional de la pena de prisión perpetua prevista en el artículo 80 CP. Señaló que esta colisiona con el principio de culpabilidad, con la división de poderes, el principio de resocialización de la pena y con la prohibición de tratamientos crueles, inhumanos o degradantes. Respecto de la culpabilidad, señaló que el límite fijo de la pena impedía valorar las circunstancias particulares de cada caso, que nunca es el mismo, violando así el artículo $19 \mathrm{CN}$. Respecto a la división de poderes, señaló que el legislador venía a arrogarse una prerrogativa que no le era propia: la individualización de la pena, violando así el artículo 116 CN. Con respecto a la resocialización (artículo $18 \mathrm{CN}$ ), esta venia banalizada ante una pena de duración inusitada. Finalmente, con relación a la prohibición de la tortura y otros tratos crueles, señaló que una pena de por lo menos 35 años, en la que aún cumplidos no garantizan un recobro a la libertad, violenta la dignidad humana tutelada por el artículo 5 de la CADH (Torre, 2016, p. 56).

La Sala IV de la Cámara Federal de Casación Penal, en el caso "Soto Trinidad, Rodolfo", causa 675/2013 del 20 de diciembre de 2013, se refirió al artículo 56 bis de la ley 24.660 en cuanto a la prohibición de acceso a las salidas transitorias y al régimen de semilibertad para quienes habían sido condenados con pena perpetua. La Sala señaló que el artículo 56 bis vulneraba los principios constitucionales de igualdad ante la ley, razonabilidad republicana, la finalidad reeducativa de la pena y el sistema progresivo de readaptación social. Concretamente, precisó que el artículo 56 bis se fundaba en una lógica de tipo de autor en la que solo con base en el delito cometido se negaba el acceso a la persona condenada a beneficios previstos por la propia normativa penal y ello contrariaba la finalidad reeducativa de la pena (Argenti y Blanco, 2015, p. 250; Ejecución de penas, 2014, p. 43).

En el año 2013 un nuevo procedente fue sentado, pero esta vez en el ámbito internacional por la Corte Interamericana de Derechos Humanos que, en el caso "Mendoza y otros vs. Argentina" (sentencia Serie C 260, de 14 de mayo de 2013), determinó que la pena de prisión perpetua a menores de edad resultaba contraria a la Convención Americana de Derechos Humanos (Elhart, 2014, pp. 1-3; Argenti y Blanco, 2015, p. 248).

Más recientemente, la Corte de Justicia de Salta, en el caso Cañarima (causa No 39417, sentencia de 13 de mayo de 2019), se pronunció por la inconstitucionalidad del artículo 14, segunda parte, del Código Penal y del artículo 56 bis de la ley 24.660 en virtud de que vulneraban el principio de reinserción social. La 
Corte indicó que los diversos beneficios penitenciarios son institutos dirigidos al logro de la reinserción social pero las limitaciones previstas para su acceso son un obstáculo insalvable que condiciona de antemano la evolución de la persona detenida, haciendo irrelevante cualquier esfuerzo personal del individuo, y ello es:

(...) incompatible con el diseño constitucional expuesto (...) de donde surge que dicha modalidad debe regirse por un principio progresivo para todos los condenados. En verdad, el legislador ha pretendido trazar una línea divisoria entre los condenados por los delitos enumerados en la referida disposición legal, del resto de los penados. Dicha escisión configura un evidente menoscabo al derecho de todo condenado a ser tratado en igualdad de condiciones que los demás (p. 8, expte. CJS, 39.417/18, Cañarima).

\section{Reflexiones sobre la cadena perpetua en el caso argentino}

Como puede verse, el sistema penal argentino dispone de diversas asimetrías. Por un lado, se reconoce el acceso a diversos beneficios penitenciarios que, posteriormente, vienen negados en la mayoría de las hipótesis que son sancionadas con la cadena perpetua. Por otro lado, se reconoce la posibilidad de acceder a la libertad condicional como un mecanismo para favorecer la reinserción social pero que viene negada absolutamente en caso de que la persona sea reincidente. Aún en el caso de que la persona no fuera reincidente, si su conducta se ubica en alguno de los supuestos del artículo $14 \mathrm{CP}$ (que, nuevamente, reproducen la mayoría de hipótesis sancionadas con la cadena perpetua junto con una pluralidad de delitos incluidos con motivo de la ley 27.375) tampoco tendrá posibilidad de acceder a la condicional. Igualmente, tratándose de la libertad asistida, tampoco se podrá acceder a ella, de acuerdo con el artículo 56 bis de la ley 24.660, por la comisión de muchos de los delitos que son sancionados con cadena perpetua. En estos casos, la única posibilidad de salir de prisión para el condenado es por vía del indulto o la amnistía.

En el supuesto del artículo 14 CP, así como en el 56 bis de la ley 24.660, nos encontramos de frente a un automatismo legislativo cuya consecuencia es una pena fija y no graduable por vía judicial. Además, los delitos a los que resultan aplicables, si bien es cierto que deben ser seriamente reprobables, se caracterizan por su amplia heterogeneidad (una situación que, como hemos dicho, ha sido profundizada con la ley 27.375 que, entre muchas otras modificaciones, incluye nuevos delitos al catálogo del artículo 56 bis de la ley 24.660). Esta característica, así como otras tantas, plantean diversos conflictos de cara a los derechos fundamentales y principios liberales del derecho penal (Argenti y Blanco, 2015, p. 243). 
La Constitución Argentina, así como la $\mathrm{CADH}$, disponen la finalidad de reinserción social de la pena. Igualmente lo hace la ley 24.660 que, incluso, dispone en su artículo 12 un régimen destinado a tal efecto (Alajia, 2014, p. 99). Este proceso de reinserción social ha sido pensado para lograr rehabilitar al detenido y lograr que un día pueda reincorporarse a la sociedad; sin embargo, el objetivo se ve coartado por disposiciones que la misma ley prevé.

Se piensa, primeramente, en el caso de la cadena perpetua "básica", en la que solo después de compurgados 35 años de prisión puede solicitarse la libertad condicional. El término de 35 años plantea en sí mismo serias dudas respecto de su proporcionalidad. Ese término es la mitad de la vida de un hombre promedio y, no obstante, viene a ser el requisito mínimo a cumplirse para eventualmente acceder a la libertad condicional. En las demás hipótesis de prisión perpetua ni siquiera puede accederse a ese requisito mínimo porque las posibilidades de libertad están restringidas. En el caso del concurso de delitos, el límite máximo es la excepción a la excepción, pues prevé la pena de hasta 50 años que es, en términos lisos y llanos, la vida de la persona. Por si fuera poco, el régimen de reclusión por tiempo indeterminado ni si quiera es visto como una pena, sino como una medida "accesoria" que acompaña —indefinidamente-a la persona sin importar el delito que ha cometido, sino solo su peligrosidad.

En esta lógica, parece ser que quien ha cometido un gravísimo crimen contra la sociedad debe pagar con la propia vida en prisión, haciendo latente la finalidad retributiva de la pena y sacrificando toda posibilidad de readaptación social. Estas normas resultan irracionales, arbitrarias, eternas, equivalentes a la muerte civil del individuo, ajenas a la posibilidad de cambio de la persona, y contrarias a toda posibilidad de reinserción social.

De ahí que la prisión perpetua en la legislación argentina se confronte con diversos principios constitucionales y liberales del derecho penal, tales como el principio de proporcionalidad (artículo $19 \mathrm{CN}$ ), el principio de igualdad (artículo $16 \mathrm{CN}$ ), la intangibilidad de la persona y la prohibición de penas contrarias a la dignidad humana (artículo $18 \mathrm{CN}$ ), así como la reinserción social del delincuente (artículo $21 \mathrm{CN}$ ) como objetivo de aquella (Zaffaroni, 2009, pp. 43, 44 y 197).

La razonabilidad implica que una pena deba guardar proporción respecto del hecho delictivo al que se pretende aplicar (Bidart, 1974, p. 118; Sabsay, 2011, p. 273; Lascano, 2005, p. 116). En el caso de la pena perpetua, no resulta razonable, en términos de un Estado constitucional y democrático de derecho, un límite de 35 años para poder acceder a una eventual libertad condicional, mucho menos 50 años de pena para el caso de concurso de delitos o una duración indefinida si nos abocamos a la sanción accesoria por tiempo indeterminado (Pazos Crocito, 2009, p. 376 y ss.). 
La heterogeneidad de las conductas tipificadas, así como las diversas condicionantes para el acceso a los beneficios penitenciarios, crean adicionalmente regímenes especiales que, en la práctica, se traducen en condenados a pena perpetua que, en algunos casos, pueden acceder a todos los beneficios; en otros, se niega el acceso a la libertad condicional pero no de otros beneficios (como la libertad asistida) y en el peor de los casos se niegan todos los beneficios. De este modo, las consecuencias jurídicas resultan diversas, dependiendo únicamente del título del delito aplicable, lo que vulnera tajantemente el principio de igualdad ante la ley (Gobbi, 2014, pp. 1-2).

La intangibilidad de la persona viene claramente lesionada al someterla a un régimen en el que no tiene ninguna certeza - salvo la muerte- de cuándo terminará su condena. La pena debe de ser cierta en el sentido de que debe fijarse con certeza el arco temporal durante el cual vendrá aplicada. El condenado debe de saber, desde el momento de la condena, el tiempo que deberá transcurrir, así como los requisitos que deberá de observar para poder acceder un día a la libertad. La normativa penal argentina permite la existencia de una pena indeterminada, cuya duración exacta no se conoce (salvo que es perpetua) y que, en ciertos casos, vuelve irrelevante cualquier comportamiento del condenado que le permita reducir la pena. En este escenario la pena es un fin en sí mismo, se convierte en una mera instancia retributiva dirigida solo a causar aflicción (Binder, 2004, pp. 301-302). La persona deja de ser considerada un ser con dignidad y pasa a ser vista como un enemigo público y social al que se debe completamente destruir (Caterini, 2016, p. 147 y ss.; Mongillo, 2009, p. 176). Precisamente es esta la ratio que caracteriza el instituto de la cadena perpetua en el ordenamiento argentino. El senador Pichetto, durante los debates parlamentarios por los que se aumentó el término para solicitar la condicional en casos de cadena perpetua, señaló:

(...) consideramos que sobre estos sujetos que cometen delitos aberrantes tiene que recaer la reclusión perpetua y el techo de los treinta y cinco años. Aquí no dudamos. No tenemos ningún conflicto moral ni ético, ni nos preocupa demasiado el tema de la resocialización, porque estos sujetos no se resocializan (...). La verdad es que en esta temática no me preocupa la resocialización de este tipo de sujetos, porque creo que no tienen cura (Alajia, 2014, p. 103).

\section{Breves reflexiones finales}

Tanto la legislación argentina como la italiana prevén la figura de la cadena perpetua y, en ambos casos, disponen mecanismos que permiten eventualmente recuperar la libertad. Respecto de esta "reducibilidad" hemos hecho ya los comentarios pertinentes; en esta sede únicamente abordaremos reflexiones en torno al instituto de la cadena perpetua en sí. 
Sí la Constitución, tanto argentina como italiana, determina que la función de la pena debe tender a la reeducación del individuo; sí, además, dispone que las penas no pueden consistir en tratamientos contrarios al sentido de humanidad; sí se dispone la prohibición de la pena de muerte, y sí se defienden la existencia de derechos inviolables del ser humano fundados en su dignidad intrínseca, la pena de cárcel a perpetuidad resulta enteramente incompatible (Zaffaroni, 2013, p. 23 y ss.; Faraguna y Gialuz, 2012, pp. 993 y ss.; Ferrajoli, 1992, p. 295).

El ergastolo no es, en esencia, muy diverso de la pena de muerte; es la expresión de un carácter eminentemente retributivo en el que por haber cometido un gravísimo delito se paga con la vida en prisión, su idea de fondo es el sacrificio, la eliminación civil de la persona mediante su definitiva expulsión del contexto social (Dolcini, 2018, p. 25; Risicato, 2015, p. 1249; Pulitanò, 1981, pp. 160 y ss.; Padovani, 2018, p. 28).

El derecho penal liberal tiene como presupuesto la defensa social sin menoscabar la dignidad inherente de la persona. Por ello, justificamos la pena como un instrumento dirigido a la reeducación, reconociendo que, por esa dignidad, toda persona tiene la posibilidad (la esperanza) de que, a pesar de los crímenes más atroces que haya cometido, pueda ser reintegrada y continuar un proyecto de vida digno para sí y para la comunidad (Ruotolo, 2014, p. 459).

El ergastolo es la pena "hasta la muerte"; esta pena supone la negación de toda idea de posibilidad de recuperación social (Brucale, 2019 p. 1314). Es la rendición del Estado de cara a tal propósito, es admitir la negación de la igual condición humana aceptando que, en algunos casos, el ser humano puede cambiar y, en otros, que solamente cabe la condena a muerte porque no existe esperanza alguna de resocialización (Chinnici, 2015, p. 4).

La subsistencia de la cadena perpetua desmitifica los postulados sobre los cuales han sido construidos los Estados liberales modernos (los derechos fundamentales del individuo y su dignidad). La cadena perpetua es el aún reclamo de la retribución, de la venganza social, de la anulación del individuo visto como enemigo del cual debemos protegernos y anularlo (Mosconi, 2008, p. 20; Risicato, 2015, p. 1248 y ss.; Pavarini, 2006, p. 7 y ss.).

Si bien es cierto que la actual figura de la cadena perpetua admite la posibilidad de que el condenado pueda un día recobrar su libertad, esta situación, sin embargo, no permite superar una tensión de fondo existente entre una figura ideada in primis para separar a perpetuidad el individuo de la sociedad y la función reeducativa de la pena (Palazzo, 2016, p. 554; Catedráticos de Derecho Penal, p. 19). 
Solo mediante una operación compleja y contradictoria se ha intentado justificar la compatibilidad de la pena perpetua. Esta operación ha consistido precisamente en negar su perpetuidad bajo determinadas condiciones; en este procedimiento cabe preguntarnos ¿qué sentido tiene mantener esta figura en el sistema penal si el único argumento con el que puede justificársele es con su negación?

La solución tampoco pasa, como podría fácilmente pensarse, sustituyendo el ergastolo con penas de hasta 50 años como ocurre en la legislación argentina y que, en la práctica, resultan formas disimuladas de cadena perpetua. Figuras como esta, aun gozando de un amplio consenso popular, no pueden mantenerse, porque, de una parte, se constituyen únicamente como disposiciones simbólicas cuyos efectos en la inhibición del crimen solo es aparente (Risicato, 2015, p. 1249) y, de otra parte, porque su colisión con los derechos fundamentales resulta evidente y, como hemos recordar, estos derechos se constituyen en esferas inviolables del individuo, más allá de toda consideración utilitaria o mayoritaria (Pulitanó, 2018, p. 16.).

La pena no puede ser pensada aún como retribución del mal causado, como un fin en sí mismo, ni mucho menos que venga acompañada de condiciones vejatorias o degradantes. La Constitución italiana y la argentina imponen una finalidad a la pena que se contraría absolutamente en el caso del ergastolo.

\section{Bibliografía}

Alagia, A. (2014). Determinación judicial de la pena y ejecución de la pena, compendio de doctrinas. Buenos Aires: Infojus.

Alderete Lobo, R. (2017). Reforma de la ley 24.660. El fin del derecho de ejecución penal en Argentina. En A. Ledesma y M. Lopardo, El debido proceso penal, tomo 5. Buenos Aires: Hammurabi.

Argenti, N. y Blanco, N. (2015). La sentencia y la selección punitiva: penas de reclusión, prisión y perpetuas. Revista Anales de la Facultad de Ciencias Jurídicas y Sociales de la Universidad Nacional de La Plata (pp. 1-17). Buenos Aires: La Ley.

Avitabile, L. (2014). Riflessioni per una "filosofia della pena". Rivista italiana per le scienze giuridiche. № 5 (pp. 235-243). Italia: Jovene Editore.

Bazán, V. (2010). El derecho internacional de los derechos humanos desde la óptica de la Corte Suprema de Justicia de Argentina. Estudios constitucionales, vol. 8, No 2 (pp. 359-388). Talca: Centro de Estudios Constitucionales de la Universidad de Talca. 
Beccaria, C. (2015) (1764). Tratado de los delitos y de las penas. Madrid: Universidad Carlos III de Madrid.

Bessone, N. y Durán, G. (2014). La reincidencia simple a la luz del fallo Gramajo. Crítica Penal, No 3. Mar del Plata: EUDEM.

Bidart Campos, G. (1974). Manual de Derecho Constitucional Argentino. Buenos Aires: Ediar.

Bontempelli, M. (2017). Diritto alla rieducazione e liberta di non collaborazione. Rivista italiana di diritto e procedura penale (pp. 1527-1530). Italia: Giuffre Editore.

Brucale, M. (2019). L'ergastolo in Europa e il "right to hope". La sentenza "Petrukov v. Ukrain" nel panorama giurisprudenziale della Corte EDU. Rivista italiana di diritto e procedura penale (pp. 1303-1314). Italia: Giuffre Editore.

Catedráticos de derecho penal, (2018). Manifiesto contra la prisión permanente revisable. Foro FICP, № 1 (pp. 18-20). Madrid: FICP.

Caterini, M. (2004). Reato impossibile e offensività. Un 'indagine critica. Napoli: Edizione scientifiche italiane.

Caterini, M. (2016). La criminalización de lo diferente. Revista de derecho penal y criminología, año VI, No 8 (pp. 147-159). España: UNED.

Caterini, M. (2017). Effettività e tecniche di tutela nel diritto penale dell'ambiente. Contributo ad una lettura costituzionale orientata. Napoli: Edizione scientifiche italiane.

Cavaliere, A. (1998). Riflessioni sul ruolo dell'offensività nella teoria del reato costituzionalmente orientata. En G. Insolera (ed.), Costituzione, diritto e processo penale. Milano: Giuffré Editore.

Chinnici, D. (2015). I "buchi neri" nella galassia della pena in carcere: ergastolo ostativo e condizioni detentive disumane. Archivio penale, No 1 (pp. 1-21). Italia: Pisa university press.

Contreras Cuenca, M. M. (2012). Análisis del fallo de la Corte tucumana que declara la inconstitucionalidad de la reincidencia. Pensamiento penal, 12 de marzo. Argentina: Asociación civil pensamiento penal.

Curotto, P. (2012). Las penas de prisión perpetuas y consecuencias jurídicas equiparables vs. normas constitucionales. Pensamiento penal, 1 de junio. Argentina: Asociación civil pensamiento penal. 
Di Nuovo, S. (2012). Ri-educazione e prevenzione: miti in cerca di senso. Minorigiustizia, No 3 (pp. 299-302). Italia: Francoangeli.

Dolcini, E. (2017). L'ergastolo ostativo non tende alla rieducazione del condannato. Rivista italiana di diritto e procedura penale (pp. 1500-1504). Italia: Giuffre Editore.

Dworkin, R. (2007). Cosa sono i diritti umani. Ragion pratica, No II (pp. 469-480). Italia: Il Mulino.

Ejecución de penas privativas de libertad (2014) Boletín electrónico de jurisprudencia, Ministerio Público de la Defensa.

Elhart, R. (2014). Sobre la imposibilidad de imponer pena de prisión perpetua a los menores punibles y el fallo de la Corte Interamericana de Derechos Humanos en el caso Mendoza y otros vs. Argentina de fecha 14 de mayo de 2013. Revista pensamiento penal, 3 de marzo (pp. 1-5). Argentina: Asociación civil pensamiento penal.

Faraguna, P. y Gialuz, M. (2012). Il carcere e la promessa tradita della Costituente. Il Mulino, Fascicolo 6, novembre-dicembre (pp. 993-1002). Italia: Il Mulino.

Ferrajoli, L. (1985). Il diritto penale minimo. Dei delitti e delle pene, № 3, pp. 493-524. Napoli: Edizioni Scientifiche Italiane.

Ferrajoli, L. (1989). Diritto e ragione. Roma-Bari: Editore Laterza.

Ferrajoli, L. (1992). Ergastolo e diritti fondamentali. Dei delitti e delle pene, № 2 (pp. 295-304). Napoli: Edizioni Scientifiche Italiane.

Ferrajoli, L. (2011). Principia iuris. Teoría del derecho y de la democracia. Vol. I. Trad., de Perfecto Andrés Ibáñez. Madrid: Trotta.

Fiandaca, G. (1991). Commento all'art. 27 comma 3. En G. Branca, Commentario alla Costituzione (a cura di Branca e Pizzorusso) (p. 342 y ss.). Bologna: N. Zanichelli.

Figari, E. y Herrera H. (2017). Análisis crítico sobre las reformas a la Ley de Ejecución de la Pena Privativa de la Libertad introducidas por la Ley No 27.375 (B.O. 28/07/2017). Pensamiento penal, 24 de noviembre. Argentina: Asociación civil pensamiento penal.

Fiorella, A. (2018). Rieducatività della pena, orientamento del destinatario del precetto e componenti sostanziali del reato. Archivio penale, sup. № 1 (pp. 97-110). Italia: Pisa university press. 
Fiorentin, F. (2019). Sicurezza e diritti fondamentali nella realtà del carcere: una coesistenza (im)possibile? Diritto penale e processo, No 11 (pp. 1596-1607). Milano: Ipsoa.

Flick, G. M. (2009). Dei diritti e delle paure. En S. Moccia (a cura di), I dirittifondamentali della persona alla prova dell'emergenza (pp. 65-84). Napoli: Edizione scientifiche italiane.

Franco Serrano, M. T. (2019). Breves aspectos sobre la constitucionalidad de la prisión permanente revisable. Foro FICP, № 3 (pp. 398-615). Madrid: FICP.

Galliani, D. y Pugiotto, A. (2017). Eppure qualcosa si muove: verso il superamento dell'ostatività ai benefici penitenziari. Revista AIC, No 4 (pp. 1-56). Italia: AIC.

Garzón Valdés, E. (1993). Representación y democracia. En E. Garzón Valdés, Derecho, ética y política. Madrid: Centro de Estudios Constitucionales.

Gobbi, O. (2014). La pena perpetua en Argentina. Análisis normativo. Diario DPI (pp. 1-2). Argentina.

González Stier, D. (2018). El control constitucional de la prisión perpetua. Diario DPI, No 203 (pp. 1-4). Argentina.

Höffe, O. (2001). La democrazia nell'era della globalizzazione. Torino: Il Mulino.

Landa Gorostiza, J. (2007). Fines de la pena en fase de ejecución penitenciaria: reflexiones a la luz de la prisión permanente revisable. Revista de derecho penal y criminología, No 18 (pp. 91-140). España: UNED.

Lascano, C. (2005). Derecho penal, Parte general. Córdoba: Advocatus.

Lauria Masaro, M. (2015). La implementación de las decisiones adoptadas en el sistema interamericano de derechos humanos: el caso Arce. Revista MPD, № 53. Argentina: Ministerio Público de la Defensa.

Maldonado Smith, M. E. (2015). Torres de babel. Estado, multiculturalismo y derechos humanos. México: Universidad Nacional Autónoma de México.

Manacorda, S. (2015). Cesare Beccaria e la pena dell'ergastolo. Jus, № 2 (pp. 165-182). Italia: Universitá cattolica del Sacro Cuore.

Marinucci, G. (1974). Politica criminale e riforma del diritto penale. Ius (pp. 463-498). Italia: Vita e Pensiero. 
Mir Puig, S. (1999). Derecho penal, Parte general. Barcelona: Tirant lo Blanch.

Moccia, S. (1992). Il diritto penale tra essere e valore. Funzione della pena e sistematica teleologica. Napoli: Edizione scientifiche italiane.

Moccia, S. (1995). Dalla tutela di beni alla tutela di funzioni: tra illusioni postmoderne e riflussi illiberali. Rivista italiana di diritto e procedura penale (pp. 343-374). Italia: Giuffre Editore.

Moccia, S. (1997). La perenne emergenza. Tendenze autoritarie nel sistema penale. Napoli: Edizione scientifiche italiane.

Moccia, S. (2009). I diritti fondamentali della persona alla prova dell'emergenza. Napoli: Edizione scientifiche italiane.

Mongillo, V. (2009). La finalità rieducativa della pena nel tempo presente e nelle prospettive future. Critica del diritto (pp. 173-228). Napoli: Edizione scientifiche italiane.

Mori, M. S. y Alberta, V. (2019). Prime osservazioni sulla sentenza Marcello Viola C. Italia (n. 2) in materia di ergastolo ostativo. Giurisprudenza penale, No 6 (pp. 1-9).

Mosconi, G. (2008). Il massimo della pena. Studi sulla questione criminale, III, № 1 (pp. 17-32). Italia: Carocci Editore.

Muñoz Conde, F. y García Arán, M. (2002). Derecho penal. Parte general. $5^{\circ}$ ed. Valencia: Tirant lo Blanch.

Musumeci, C. (2012). Ergastolo, giorno e notte. Giustizia insieme, fasc. 1 (pp. 25-46). Roma: Aracne editrice.

Naucke, W. (2002). Strafrecht. Eine Einführung, 10a ed. Neuwied-Kriftel: Luchterhand.

Nicotra, I. (2014). Il senso della pena. A un anno della sentenza Torreggiani. Rivista AIC, No 2. Italia: AIC.

Nino, C. S. (1989). Ética y derechos humanos. Un ensayo de fundamentación. Barcelona: Astrea.

Nuvolone, P. (1982). Voce Pena (in generale). Enciclopedia del diritto, tomo XXXII. Milano: Giuffré. 
Padovani, T. (2018). Ergastolo in luogo della pena di morte: una eredità giacente. En C. Paliero; F. Viganó; F. Basile y G. Gatta, La pena, ancora: tra attualità e tradizione. Studi in onore di Emilio Dolcini (pp. 27-34). Milano: Giuffré.

Palazzo, F. (2016). Corso di diritto penale, parte generale. $6^{\text {a }}$ ed. Torino.

Palombino, G. (2017). Ergastolo ostativo e funzione "variabile" della pena: una prospettiva costituzionale ed europea. Diritto Pubblico Europeo Rassegna Online.

Pavarini, M. (2006). La neutralizzazione degli uomini inaffidabili. La nuova disciplina sulla recidiva e altro ancora sulla guerra alle Unpersonen. Studi sulla questione criminale, I, n. 2 (pp. 7-30). Italia: Carocci Editore.

Pazos Crocitto, J. I. (2009). Derecho Penal. Aparte general en cuadros sinópticos. $2^{\text {a }}$ ed. Argentina: Induvio Editora.

Petrino, R. (2003). Artículo 11. Protección de la honra y de la dignidad. En E. Alonso Regueira, La Convención Americana de derechos humanos y su proyección en el derecho argentino (pp. 203-217). Buenos Aires: La Ley.

Pulitanó, D. (1981). Ergastolo e pena di morte. Le "massime pene" tra referendum e riforma. Democrazia e diritto (pp. 155-171). Milano: Franco Angeli.

Pulitanó, D. (2018). Minacciare e punire. En C. Paliero; F. Viganó; F. Basile y G. Gatta, La pena, ancora: tra attualità e tradizione. Studi in onore di Emilio Dolcini (pp. 1-26). Milano: Giuffré.

Pugliotto, A. y Musumeci, C. (2015). Gli ergastolani senza scampo - Fenomenologia e criticitá costituzionale dell'ergastolo ostativo. Napoli: Editoriale scientifica.

Pugliotto, A. (2017). Tre telegrammi in tema di ergastolo ostativo. Riv. It. Dir. proc. pen. (pp. 1518-1521). Milano: ed. Giuffré.

Quiñones Allende, G. (2013). El mandato de certeza y la ejecución de la pena. Infojus, DACC130316 (pp. 1-11).

Quiroga Lavié, H. (2009). Derecho Constitucional Argentino. T. 1. Santa Fe: Rubinzal-Culzoni.

Racca, I. (2014). Los delitos no resocializables. Pensamiento penal, № 3, pp. 1-24. Argentina: Asociación civil pensamiento penal.

Ragimov, I. (2015). Filosofia dei delitti e delle pene. Torino: Giappichelli

Ragimov, I. (2016). La moralità della pena. Torino: Giappichelli. 
Risicato, L. (2015). La pena perpetua tra crisi della finalità rieducativa e tradimento del senso di umanità. Rivista Italiana di diritto e procedura penale (pp. 1238-1258). Italia: Giuffre Editore.

Rodríguez Yague, C. (coord.) (2016). Contra la cadena perpetua. Cuenca.

Ruotolo, M. (2014). Riflettendo sul senso della pena e sui diritti dei detenuti. Ragione pratica, fasc. 2 (pp. 455-469). Bologna: Il Mulino.

Sabsay, D. (2011). Manual de derecho constitucional. Buenos Aires: La Ley.

Santini, S. (2019). Anche gli ergastolani ostativi hanno diritto a una concreta via di scampo: dalla Corte di Strasburgo un monito al rispetto della dignità umana. Diritto Penale Contemporaneo, 1 julio. Milano: Associazione Diritto penale contemporaneo.

Scordamaglia, V. (2016). La tensione rieducativa della pena. La giustizia penale, fasc. IV (pp. 110-128). Roma: Soc. edit. La Giustizia Penale.

Serrano Pérez, I. (2018). La prisión permanente revisable: su regulación en nuestro ordenamiento jurídico y en el Derecho comparado europeo. Foro FICP, No 3. Madrid: FICP.

Sgubbi, F. (1998). El delito como riesgo social. Santiago de Chile: Olejnik.

Spangher, G. (2019). Sicurezza, dignità e identità personale. Diritto Penale e processo, No 11 (pp. 1567-1571). Milano: Ipsoa.

Torre, L. A. (2016). La viabilidad constitucional de las penas de prisión perpetua y temporales como reproche. Argentina: Universidad siglo XXI.

Trapani, M. (2018). La rieducazione del condannato: tra "ideologia correzionalistica" del trattamento e garanzie costituzionali di legalità e sicurezza. Rivista Italiana di diritto e procedura penale, № 3 (pp. 1693-1719). Italia: Giuffre Editore.

Travaglia Cicirello, T. (2019). La funzione rieducativa della pena, le rigidità del ergastolo e l'opera correttiva della giurisprudenza costituzionale. Diritto Penale e processo, № 3 (pp. 363-372). Milano: Ipsoa.

Urbinati, F. (2018). L'imperativo costituzionale della rieducazione: un necessario intervento della Corte Costituzionale sulla irragionevolezza degli sbarramenti ex art. 58-quater, comma 4, ord. Penit. Processo penale e giustizia, № 6 (pp. 1100-1104). 
Vianello, F. y Padovan, D. (1999). Criminalità e paura: la costruzione sociale dell'insicurezza. Dei Delitti e delle Pene, № 12 (pp. 247-286). Milano: Centro Sociale Ambrosiano-Milano.

Von Jhering, R. (1972) Lo scopo nel diritto, 1877. Torino: Ed. It.

Zaffaroni, E. R. (1995). Los objetivos del sistema penitenciario y las normas constitucionales. El Derecho Penal Hoy (pp. 115-129). Buenos Aires: Editores Del Puerto.

Zaffaroni, E. R. (2008). Derecho Penal. Parte General. Buenos Aires: Ediar.

Zaffaroni, E. R. (2009). Estructura básica del derecho penal. Buenos aires: Ediar.

Zaffaroni, E. R. (2013). El máximo de la pena de prisión en el derecho vigente. La justicia uruguaya, No 147 (pp. 23-36). Uruguay: La justicia uruguaya.

\section{Jurisprudencia}

\section{Argentina}

CSJN, "Estévez, Cristian Andrés o Cristian Daniel s/robo calificado por el uso de armas". Fallos 333: 866, sentencia del 8 de junio de 2010.

CSJN, "Maldonado, Daniel Enrique y otro s/Robo agravado por el uso de amas en concurso real con homicidio calificado". Fallos 328: 4343, sentencia del 7 de diciembre de 2005.

CSJN, “Giménez Ibáñez, Antonio Fidel". Fallos 329: 2440, sentencia del 4 de julio de 2006.

CSJN, "Gramajo, Marcelo Eduardo s/robo en grado de tentativa". Fallos 324: 2153, sentencia del 5 de septiembre de 2006.

Cámara 11 Criminal de Córdoba, "Bachetti Sebastián Alejandro y otra p.ss.aa de Homicidio calificado por el vínculo", sentencia del 2 de noviembre 2007.

Cámara Federal de Casación Penal, Sala II, caso "Montiel, Alejandro Héctor", sentencia del 26 de noviembre 2012.

Cámara Federal de Casación Penal, Sala IV, caso "Soto Trinidad, Rodolfo", sentencia del 20 de diciembre de 2013. 
Tribunal Criminal N. 1 de Necochea, "Etcheverry, Daniel; González, C, y Varela, M. s/homicidio calificado por el concurso premeditado de dos o más personas; lesiones graves culposas y robo", sentencia del 13 de mayo de 2013.

Corte de Justicia de Salta, caso Cañarima, sentencia del 13 de mayo de 2019.

\section{Italia}

Corte Const., sentencia n. 313 de 2 de julio de 1990.

Corte Const., sentencia n. 264 de 21 de noviembre de 1974.

Corte Const., sentencia n. 168 de 28 abril de 1994.

Corte Const., sentencia n. 135 de 9 de abril de 2003.

Corte Const., sentencia n. 273 de 20 de julio de 2001.

Corte Const., sentencia n. 149 de 11 de julio de 2018.

Corte Const., sentencia n. 253 de 23 de octubre de 2019.

\section{Internacional}

TEDU, sentencia Campbell e Fell vs. Reino Unido, 28 de junio de 1984.

TEDU, sentencia Kafkaris vs, Cipre, 12 febrero de 2008.

TEDU, sentencia Vinter $v s$. Reino Unido, 9 de julio de 2013.

TEDU, sentencia Viola vs. Italia, 13 de junio de 2019.

CoIDH, sentencia Mendoza y otros vs. Argentina, 14 de mayo de 2013.

Fecha de recepción: 07-02-2020 Fecha de aceptación: 24-06-2020 